\title{
REVIEW
}

\section{ENVIRONMENTAL POLLUTANTS AND BRAIN CANCERS: WHERE DO WE STAND?}

\author{
M. Migliaccio, S. J. Williams, V. Caracciolo
}

Sbarro Institute for Cancer Research and Molecular Medicine, Center of Biotechnology, College of Science and Technology, Temple University, Philadelphia, PA, USA

\section{CORRESPONDING AUTHOR:}

Stephen J. Williams

Sbarro Institute for Cancer Research and Molecular Medicine

Center of Biotechnology, College of Science and Technology

Temple University

1801 N. Broad Street

19122 Philadelphia, PA, USA

E-mail: tug83586@temple.edu

ORCID: 0000-0003-1129-9864

Doi: $10.48286 / a r o .2021 .30$

History

Received: Oct 26, 2021

Accepted: Nov 19, 2021

Published: Dec 1, 2021

\section{ABSTRACT}

The global burden of Tumors of the Central Nervous System has increased in the past 25 years. Their prognosis is usually poor, and the less aggressive tumors can lead to severe cognitive and physical disabilities. The etiopathogenesis of CNS tumors is still largely unknown. Genetic factors and ionizing radiation are currently the only well-established risk factors for brain tumors. Several compounds present in the environment have been studied as possible causative agents of CNS tumors, often with inconclusive results. In this review, we focus the attention on certain categories of environmental pollutants for which new data emerged in the recent years, possibly integrating and reinforcing the actual hypothesis that links these factors to brain tumors. Pollutants are present in the environment as a result of both natural phenomena and human activities. We review the role that some categories of pollutants, such as particulate matter, heavy metals, pollutants in the food chain production, and electromagnetic fields may have in the onset of brain tumors. Although many evidences suggest a possible association between specific pollutants and some brain tumors, a clear associative role has not been established yet. 


\section{KEY WORDS}

Brain cancer; risk factors; environmental pollution; electromagnetic fields.

\section{IMPACT STATEMENT}

The lack of strong causality between environmental exposures and brain cancer has hampered ability to support risk assesments and actionable policies, however recent well-controlled epidemiologic studies suggest correlations worthy of additional in-depth cosiderations.

\section{INTRODUCTION}

Tumors of the Central Nervous System (CNS) affect the brain or the spinal cord and may occasionally disseminate within the cerebrospinal fluid (1). They can be either malignant or benign. Gliomas represent the most common types of primary tumors of the CNS, and account for approximately 33\% of all CNS tumors. Named upon their cell of origin, they include glioblastoma, astrocytoma, and oligodendroglioma. The remaining tumors of CNS include other tumors of glial origin, such as ependymomas and schwannomas, and tumors of various histology, such as medulloblastomas, meningiomas, and CNS lymphomas (2). Over 120 types of brain tumors have been identified so far (3). The global burden of CNS tumors has increased in the past 25 years; their prognosis, especially for malignant brain tumors remains very poor, and also the less aggressive tumors can lead to severe cognitive and physical disabilities (4). According to the World Count Research Found, CNS tumors account for approximately $1.7 \%$ of cancers, and rank number 17 in the global cancer incidence report (5). Significant variations in the incidence of CNS cancers are registered in different geographical areas and they may reflect different accessibility to advanced treatment technologies, different lifestyles and environmental exposures, or genetic risk factors within the population (2). The etiopathogenesis of CNS tumors is still largely unknown. Genetic factors and ionizing radiation are currently the only well-established risk factors for brain tumors. Genetic disorders that have been associated to rare cases of brain and spinal cord cancers include: neurofibromatosis I and II, associated with neurofibromas, gliomas, schwannomas, and meningiomas; the Von Hippel-Lindau disease, associated with hemangioblastomas of the brain and the spinal cord; Li-Fraumeni syndrome, associated with astrocytic tumors, but also medulloblastomas and supraten- torial primitive neuroectodermal tumors; Turcot's syndrome, associated with medulloblastomas, astrocytomas, and ependymomas; the Gorlin's syndrome, associated with medulloblastomas (6).

The International Agency for Research on Cancer has recognized ionizing radiations the only carcinogen for brain tumors (7). The two main sources of high-intensity ionizing radiation exposure are atomic weapon radiation and previous radiation therapy. The latter has been commonly used as the standard treatment for nearly all tumor diseases. Also, reports of low-dose ionizing radiation, such from frequent airline travel, radiological terrorism, occupational exposure, and environental exposure from proximity to illegal waste dumps have been reported (8). However, its use in brain tumors causes important side effects on cognitive and functional processes, tumor relapse, more aggressive tumor behavior and, in case of children, impairment of brain development as well (9).

The increased incidence of brain tumors observed in industrialized countries dictated the need to screen several compounds in search of possible causative agents for these tumors: heavy metals, pesticides, contaminants in water, air pollution, smoking, diet, lifestyle, and many more. Measurements of occupational and environmental exposure became then two important strategies to record the health risk to the exposed employee and the general population, respectively (10). Unfortunately, with the exception of ionizing radiation, to date a clear association between specific risk factors and brain cancers has not been demonstrated yet $(2,11)$. Different circumstances contribute to the lack of data: for example the small number of patients that can be studied each time, that is not sufficient to conclude statistical analyses on large scale; the difficulty to harvest material from the CNS, especially for control groups, 
without invasive procedures, and with the risk to cause cognitive and physical damage; the fact that the detection of some toxic agents in the CNS can be performed only years after the exposure, when the brain is available for autopsy, and/or the toxic agent has been cleared by the organism (12).

On the other hand, negative associations with brain tumors have been reported for atopic conditions, such as asthma, eczema, food allergy (2). For the purpose of this review, the authors focus the attention on pollutants such as particulate matters, heavy metals, electromagnetic radiation, for which new data emerged in very recent years, possibly integrating and reinforcing the actual hypothesis linking these factors with brain tumors. Brief considerations on the actual knowledge on the role of food contaminant will also be included.

\section{ENVIRONMENTAL POLLUTION}

Pollutants are present in the environment as a result of both natural phenomena (e.g., volcanic dust, sea salt particles, photochemically formed ozone, biological decay, and more) and human activities (e.g., industrial and agriculture, burning of fossil fuels, mining, sewage). They may cause cancer and other serious diseases, may be responsible for reproductive or birth defects, and account for adverse environmental and ecological effects. For some pollutants a causative role in the pathogenesis of several diseases has been identified. For example, it has been ascertained that exposure to asbestos causes mesothelioma, cancers of the lung, larynx, and ovary (13); while exposure to paraformaldehyde causes myeloid leukemia and some other rare cancers (14), including cancers of paranasal sinuses, nasal cavity, and nasopharynx (15). To date, many evidences suggest also a possible association between specific pollutants and the onset of brain tumors, but a clear associative role has not been established yet.

\section{PARTICULATE MATTER (PM)}

Air pollution has been associated with different types of neoplastic diseases, such as lung cancer, breast cancer, liver and pancreatic cancer (16-19). The composition of air pollution varies according to the source and the rate of emission, the geographic characteristics, atmospheric conditions, and industrialization (20). Amid the components of air pollution that represent a major concern for public health, there are gaseous substances, such as carbon monoxide, ozone, nitrogen dioxide, nitric oxide, sulfur dioxide, and particulate matter (PM), which includes nitrates, sulfates, polycyclic aromatic hydrocarbons (PAHs), and metals such as iron, copper, nickel, zinc, mercury, and more (21). Based on their size in micrometers $(\mu \mathrm{m}), \mathrm{PM}$ are classified into "coarse" $\left(\mathrm{PM}_{10}\right.$, diameter $\left.<10 \mu \mathrm{m}\right)$, "fine" $\left(\mathrm{PM}_{2.5}\right.$, diameter $<2.5 \mu \mathrm{m})$ and "ultrafine" $\left(\mathrm{PM}_{0.1}\right.$, diameter < $0.1 \mu \mathrm{m}$ ) particles. Coarse particles consist mainly of insoluble crust-derived minerals, biological material (pollen, endotoxins, fungi, bacteria) and sea salts, but also include particles from industrial sources. Fine and ultrafine particles are mainly products of fossil fuels combustion $(21,22)$. The smaller the size of the particles, the greater their ability to penetrate and cross different tissues: after inhalation particles smaller than $10 \mu \mathrm{m}$ in diameter can invade the lungs and even reach the bloodstream, and fine particles represent even a greater risk to health (20). In this sense, fine and ultrafine particles, due to their ability to penetrate into the alveoli, represent a major health issue than coarse particles, which generally penetrate only in the upper respiratory system. Several studies have documented the ability of small inhaled particles to reach the brain, and possibly cause oxidative stress, neuroinflammation, and extensive neural cells damage, especially in animal models. For instance, Oppenheim et al. reported that exposure to vehicle emissions results in altered blood brain barrier permeability and expression of matrix metalloproteinases and tight junction proteins in mice (23). Other evidences on experimental animals demonstrated that a fraction of inhaled ultrafine particles generated from graphite electrodes were able to translocate to the CNS when deposited in either the nasal epithelium (via the olfactory nerve) or the alveolar epithelium, by entering into the systemic circulation and eventually crossing the blood-brain barrier (24). In humans, air pollution has been linked to stroke, and neurodegenerative diseases, such as Alzheimer's, Parkinson's diseases, and dementia $(25,26)$. Fine and ultrafine particulate matter has been found in both brain capillaries and parenchyma (27), however the mechanisms of toxicity of these particles in the brain are still under investigation. Size and composition of the particulate matter may also influence the processes of distribution and toxicity in the brain. For example, ultrafine particulate may easily penetrate cell membranes, cross lung barriers, and brain blood barrier (BBB), 
reaching the different brain compartments (28). In addition, it has been hypothesized that the intrinsic characteristics of the particulate matter can stimulate innate immune response in the brain, causing the production of inflammatory cytokines and inflammation. In particular, astroglia, brain capillaries and microglia respond to the components of air pollution by activating multiple cellular pathways, which ultimately lead to chronic neuroinflammation. Inflammation and oxidative stress are generally identified as main mechanisms through which air pollution causes cell damages (28). The effects of fine particles on the CNS are mainly consequences of a chronic exposure to air pollution (28). Based on these and other evidences, and on the increase of brain tumor incidence in industrialized countries (25), the common thought was questioning about a possible association between such a massive and constant presence of pollutants in the atmosphere with the onset of brain neoplasia. In this context, several reports have been made, some with inconclusive results. But recently, few independent studies have been carried out, in which the enrollment of a consistent number of people to analyze and monitor from different geographic areas, allowed to build significant and robust case-studies $(25,29)$. One of these studies, the ESCAPE (European Study of Cohorts for Air Pollution Effects), involved 12 patients' cohorts from 6 different countries, who had a high level of exposure to pollutants, due to the anthropomorphic activities in the participating cities. Different types of environmental pollutants were analyzed (25). The cohorts were chosen to verify a possible link between the exposure to specific concentrations of air pollutant and the presence of malignant and nonmalignant brain tumors. The pollutants examined included fine and coarse particulate matter $(\mathrm{PM}<2.5 \mu \mathrm{m}, \mathrm{PM}<10 \mu \mathrm{m})$, as well as nitrogen oxides ( $\mathrm{NO}_{2}$ and $\mathrm{NOx}$ ). The study involved 282, 194 subjects, and 466 of them developed malignant brain tumors during the 12 years of follow-up. The study used a 2-step approach: initial$l y$, the association between different air pollutants and brain tumor in each cohort was estimated, then the estimates from each cohort were combined for each pollutant and each brain tumor subtype, and compared by meta-analyses. The results showed a weak, positive association between long-term exposure to $\mathrm{PM}_{2.5}$ (a marker for traffic-related air pollution) and $\mathrm{NO}_{2}$ and brain tumors (25). In another study, Weichenthal et al. found a stronger, positive association between ultrafine particles concentra- tions in the environment and incident brain tumors (29). The study involved a cohort of approximately 1.9 million adults living in Toronto and Montreal, the two largest Canadian cities, and among the Canadian cities with the highest air pollution. The cohort was observed over a time period of 15 years (from 2001 and 2016), and during this time air pollution assessment was constantly performed. Overall, these studies suggest that traffic pollution may represent an important source of exposure for brain tumors $(25,29)$. These results were fully in accordance with a previous report from Jorgensen et al. (The Danish Nurse Cohort) in which weak positive associations were observed between exposure to $\mathrm{PM}_{2.5}, \mathrm{NO}_{2}$, and $\mathrm{NO}$ and brain tumors, and in which the stronger association was observed among obese subjects and subjects with lower levels of physical activity (30). Finally, an increased risk of malignant brain cancer has been observed in relation to long-term exposure to benzene, ozone, and possibly $\mathrm{PM}_{10}$ in men, but not in women, in a study from Wu et al. (31) involving a multiethnic cohort of people living in Hawaii or California, and with different demographic, diet, and lifestyle characteristics. These and other studies are based on statistical models that present some limitations; however, it is worth noting that all of them support the possibility that air pollution may be linked to some risk of CNS tumors. Further studies to confirm this hypothesis are certainly needed. It would also be interesting to consider different lifestyles that place people at different risk than others. For instance, people who work in the health sector, or agriculture, rather than being part of the petrochemical industry chain.

\section{Heavy metals}

Heavy metals are chemical elements with relatively high density which exert toxic or poisonous activity at low concentrations. They are naturally occurring elements with extensive uses in industrial, domestic, agricultural, medical and technological fields, then having a wide distribution in the environment (32). Common heavy metals are mercury, cadmium, arsenic, chromium, thallium, and lead. They can accumulate in the soil and in the water, entering the food chain and affecting living organisms at different grade. In humans, many heavy metals are known carcinogens, in particular for lung and skin cancers (33), and are also responsible for cardiovascular and neurological diseases $(34,35)$, as well as kidney and bones pathologies $(36,37)$. Lead and mercury are potent neurotoxins and are involved, among oth- 
er, in the onset of neurodegeneration, decreased cognitive functions, and psychiatric manifestations, including depression, anxiety and irritability (38). Several independent studies also showed an accumulation of heavy metals in brain tumor samples, confirming the ability of these metals to cross the $\mathrm{BBB}$, and the ability of the human brain to retain them $(12,39-41)$. Understanding the relationship between the occupational exposure to heavy metals and the etiology of different neurological diseases, including brain cancers, has been object of several studies. For instance, an increased risk for low grade gliomas was related to men working in the metal industry (42); prolonged exposure to arsenicum was associated to a higher risk for lung, skin, liver, bladder, and brain cancers (43); increased lead exposure was associated with increased meningioma risk (44, 45). In most cases, these kinds of studies provided inconsistent results, which are partially explained with the difficulty in detecting neurotoxic metals in diseased brains. For instance, the cells that originally contained the metals are possibly destroyed by the pathological process, or the metals may have been cleared by the brain by the time the brain is available for examination, usually after autopsy (12). The mechanism through which heavy metals and metals in general may contribute to some neuronal diseases, including Parkinson's and Alzheimer's diseases, is also unclear, but the oxidative stress caused by metals seems to play a pivotal role in neuroinflammation and cell death (39). Metals have the intrinsic ability to lose electrons and react with molecular oxygen to form reactive oxygen species (ROS), among which the superoxide anion, hydrogen peroxide, and hydroxyl radical (46). ROS are highly reactive with organic substances, such as DNA, lipids, and proteins, leading, ultimately, to their damage, and are responsible for the alteration of the redox state of the cells $(46,47)$. Peroxidation products of fatty acids, protein carbonylation and nitration, and DNA and RNA oxidative damage are some biomarkers of oxidative stress in neurodegenerative diseases (46). Increased levels of lipids, proteins and nucleic acids oxidation have been associated with elevated levels of amyloid beta protein $(A \beta)$ in Parkinson's disease $(47,48)$. Similarly, increased levels of oxidized lipids and proteins have been detected in the substantia nigra of Parkinson's disease patient $(47,49)$. Oxidative stress seems to be also involved in metal-related cancers. According to Xu et al., ROS could exert their oncogenic properties in a two-stage process: in the early stage, elevated levels of ROS determine DNA damage, inhibition of DNA repair, and alterations of signal transduction pathway, ultimately leading to cell transformation. In a second stage, low levels of ROS in metal-transformed cells promote apoptosis resistance, autophagy deficiency, inflammation and angiogenesis (50). Metal-induced oxidative stress has also been linked to epigenetic alterations and abnormal cellular growth in some tumors, especially lung tumors $(39,51,52)$. Several reports suggest that oxidative stress, by altering activity and functions of DNA methyl transferases (DNMTs), determines changes in DNA methylation (53). For example, oxidative stress induced by hydrogen peroxide increases the binding and the activity of DNMT1 on promoters of tumor suppressor genes (54); while hydroxyl radicals interfere with the DNMT-DNA binding, overall promoting a hypomethylation status (55); in some cancers, ROS-induced oxidative stress increases the levels of 8-hydroxydeoxyguanine, responsible of conformational changes which determine the shift of chromatin from an active to a repressive status (56). Histones posttranslational modifications include acetylation, methylation, phosphorylation, glycosylation, ribosylation, ubiquitination, sumoylation. These modifications regulate DNA accessibility (53). In particular, the reactions of histone acetylation are involved in the regulation of many cellular processes, such as chromatin transcription, gene silencing, cell cycle progression, apoptosis, differentiation, DNA replication and repair, nuclear import. Alterations of histone acetylation and methylation induced by oxidative stress may affect either one of the aforementioned processes, and play an important role in tumor pathogenesis and progression. Similarly, micro-RNAs (miRNAs) are known regulators of transcription, and the alteration of their expression and activity by ROS can contribute to the control of tumorigenesis (57). The analysis of the mechanisms through which each miRNA contributes to the control of tumorigenesis is beyond the purpose of this review. The authors only want to underline the fact that to date, several miRNAs have been identified, which are involved in the antioxidant response in cancer disease. A few examples are MIR-101, MIR-28, MIR-153, which are downregulated by ROS in breast cancer; MIR-200A and MIR432-3P which are upregulated by ROS in esophageal cancer; MIR-7, upregulated in neuroblastoma and non-small cell lung cancer (53). In addition, several reports indicate that miRNA levels are affected by environmental pollutants and play a critical role in determining the tumor phenotype $(58,59)$. 
Despite a role of metals in the pathogenesis of brain tumors has still to be demonstrated, as well as an eventual mechanism of action, recent studies seems to provide unquestionable evidences of the prevalence of some metals in brain tumor. Stojsavlievic et al. reported the results of a study, conducted in Serbia, in which essential trace metals (manganese, cobalto, zinco, selenio, rame) and relevant heavy metals (including aluminum, nickel, arsenic, cadmium, lead, uranium) were assessed on samples of serum, cell fraction, cerebrospinal fluid, and cancerous tissue from patients with diagnosed brain tumors and compared with results from control subjects (60). The study showed that brain tumor patients had altered profile of some metals in all kind of samples, when compared to control samples. In particular, higher contents of manganese, selenium, and lead were reported in tumor patients, with lead making possible the discrimination between tumor and non-tumor patients. These results possibly suggested the implication of these metals in the disruption of homeostasis and in the pathogenesis of brain tumors. Furthermore, uranium levels were considerably elevated in blood samples of tumor patients, and the Uranium/selenium ratio was suggested to be a possible blood marker in diagnostic evaluation of brain tumors. However, the high uranium levels found in the samples could be explained with the radioactive outbreaks that Europe experienced during the war in Serbia in 1999 (60). These results were possibly in agreement with the results previously found by Arslan et al, which reported a higher content of cadmium, manganese, lead, and zinc, a lower content in cupper, and unchanged level of cobalt in the serum of patients with malignant gliomas, as compared to serum of healthy subjects (61).

Among the heavy metals, mercury and lead are those with well-known toxic effects on the human body, and their possible involvement in brain tumors has been object of several studies. Here, we report the most significative.

\section{Mercury}

According to the Agency for Toxic Substances and Disease Registry, of the U.S. Department of Health and Human Services, arsenic, lead and mercury occupy the first three position, respectively, in the 2019 priority list of most significant potential threat to human health. This list does not rank the most toxic substances, but its prioritization is based on a combination of their frequency, toxicity, and potential for human exposure at specific facilities sites (62). Mer- cury is a natural element and it is released in the environment in its inorganic form, mainly as a result of natural processes and human activities. It can be biologically converted in organic compounds, of which the most common is methylmercury (MeHg). $\mathrm{MeHg}$ represents the major source of organic mercury found in the ecosystems. It accumulates in the food chain, increasing the toxic risks for humans (63). In general, at cellular level, mercury exposure has been associated with alterations in membrane permeability, changes in macromolecular structure due to its affinity for sulfhydryl and thiol groups, DNA damage (63), increased oxidative stress, and mitochondrial dysfunction. Brain cells seem very sensitive to cytotoxic and genotoxic effect of mercury (64). It has been hypothesized that mercury can cause epigenetic variations $(65,66)$ and DNA mutations $(39)$ that may function as a trigger for gliomas, including glioblastomas, and oligodendrogliomas, which arise from astrocytes and oligodendrocytes. This possibility was raised after some reports evidenced an increased risk of these tumors in dentists and dental nurses, who had a constant exposure to mercury included in dental amalgama (67). Other reports, however, displayed contrasting results (66). A recent study from Pamphlett (2018) (12) reported the presence of inorganic mercury in different cell types of the brain of a man who injected himself with inorganic mercury, and who died 5 months after continuous exposure to this metal, deposited in his organs. Post-mortem examination of the brain showed the presence of inorganic mercury in astrocytes, oligodendrocytes, corticomotoneurons, locus ceruleus neurons, and vertebral micro vessels (12), further demonstrating the ability of this metal to cross the BBB and efficiently localize in and be retained from brain tissue.

\section{Lead}

The International Agency for Research on Cancer (IARC) defined inorganic lead as "Probably carcinogenic to humans" (68). Neurotoxic effects of lead are well known, and may affect the development of the nervous system in children (69). In mature brain, lead may cause neurodegenerative diseases, such as Alzheimer's and Parkinson's diseases (70). However, any evidence linking lead occupational exposure to brain tumors has shown inconsistent results. For instance, a study by Steenland et al. in 2019 reported a significant positive relationship between lead exposed workers and malignant brain tumors incidence in two cohorts from different countries (71). The same positive trend was observed in other studies 
$(72,73)$. Conversely, other reports declared no association between lead exposure and CNS tumors (74, 75). Some of these inconsistencies come from limitations in study design, measurements of exposure, tumor heterogenicity and outcome, and publication biases, especially when performing meta-analysis on epidemiological studies. To our knowledge, the most recent publication on occupational lead exposure and brain tumors performs a systematic review and meta-analysis trying to overcome some of the limitations from past studies and, although with some other limitations, it provides evidence of a not significant association with lead exposure and risk of brain tumors (malignant and benign), but the risk of brain tumors resulted significantly increased when only malignant brain tumors were included (76). Once again, it would be interesting to study a specific relationship between lead exposure and the specific type of brain tumor. Lead is able to cross the blood-brain barrier and distribute in the brain parenchyma, possibly due to its ability to replace calcium ions $(76,77)$. It has been hypothesized that lead neurotoxicity may be involved in the pathogenesis of neurodegenerative disease through epigenetic modifications, inhibition of N-methyl-D-aspartic acid receptor, and increased quinolinic acid production (78), while the mechanism through which lead could cause brain tumor are unknown. Inhibition of DNA synthesis and repair, interaction and inhibition of tumor suppressor proteins, oxidative stress, alteration of signaling pathways, and induction of apoptosis are among the proposed processes involved in lead carcinogenesis $(39,76,79)$.

\section{Electromagnetc radiation pollution}

Electromagnetic radiation refers to a spectrum of waves of different energy. Based on their capacity to break atomic bonds, then removing electrons from atoms and molecules through which it passes, electromagnetic radiation is distinguished in ionizing radiation (IR) and non-ionizing radiations (NIR) (80). IR include $X$ - and gamma-rays, but also alphaand beta-particles from radioactive decay. They are radiation at very high frequency. Natural sources of IR are solar radiation and radiation emitted by nuclides of the Earth's surface. Human activities, such as mining, nuclear plants, use of radioactive materials in medicine and research, and handling, processing, and disposal of radioactive material, all contribute to increasing radioactive pollution in the environment (81). We shall not discuss here the IR effects on human health, since their ability to pose humans at very serious health risks, such death and cancer, is well-known, and we have already mentioned that IR are the only recognized causal agent for cancer. We also remark that the ability of IR to deliver high energy to tissues and cells, destroying DNA (and other biomolecules) overtime, provides a powerful tool, in medicine, to fight cancer, by killing cancer cells and shrinking the tumor $(80,82)$. Here, we rather want to focus on the long list of electromagnetic waves at lower frequencies, the NIR, which contribute to electromagnetic pollution, and for which the effects on human health are still not completely understood. NIR exert biological effects by heating, altering chemical reactions, or inducing electrical current in tissues and cells, then inducing changes in ions distribution (83). NIR include radio waves, microwaves, infrared, visible light, and ultraviolet light, and are collectively referred to as electromagnetic fields (EMFs) (84). EMFs are generated wherever electric current flows: power lines, electrical generators and motors, electrical wiring, home electronic devices, and wireless communication systems (84). The generated electric field is measured in hertz $(\mathrm{Hz})$, while the magnetic field is quantified in tesla (T). EMFs are typically distinguished in static magnetic fields (SMF) $(0 \mathrm{~Hz}$; 0.1 $10 \mathrm{mT}$ ), extremely low frequencies magnetic fields (ELF) (0-300 Hz), intermediate frequencies (IF) (300 $\mathrm{Hz}-100 \mathrm{kHz})$, and in high frequency (HF) magnetic fields (100 kHz-300 GHz) (83). There is no direct evidence of effects of EMF on human health, nor a direct link between EMF and incidence of brain tumors. However, several studies at cellular levels demonstrated some undesirable effects, some of which are briefly reported here. SMF can be measured in proximity of videos, MRI instruments, industrial electrolysis, headphones, audio-speaker components, refrigerator magnets. Exposure to SMF affects electrically charged particles and cells. For example, the magnetic force can affect the velocity of blood cells in the blood flow (85). Exposure of Human skin fibroblasts to SMF generated by routinely used MRI showed alterations in cell morphology, decreased expression of some sugar residues of glycoconjugates, decrease of thymidine incorporation and decrease of second messenger formation (86). Furthermore, strong SMF were reported to induce mutations through elevated production of intracellular superoxide radicals in E. coli (87), while a decrease of membrane mitochondrial potential was observed after exposure to low SMF in SH-SY5Y glioblastoma-like cells, and this effect was associated with increased production of ROS (88). 
ELF main sources are powerlines, domestic electric distribution, electric engines in cars, trains and tramway (83). In their paper, Odzemir et al. summarized the results reported in literature and related to the effects that ELF may have on cellular functions: these studies reported the effects of ELF on cell proliferation and differentiation, apoptosis, DNA synthesis, RNA transcription, protein expression, hormone production and other cellular processes (83). In a case control study performed by Baldi et al. on occupational and residential exposure to EMF and risk of brain tumor it was found that the risk for meningiomas was higher in subject living closer to power lines and exposed to ELF, suggesting the possibility that ELF could play a role in the occurrence of this tumor (89).

Computer monitors and TV screens, anti-theft devices, card readers, metal detectors are common sources of IF, while sources of HF, or radio frequencies, are mobile phones, radar, broadcasting and TV, microwave ovens. The increasing diffusion of these technologies goes in parallel with an increased domestic and occupational exposure to the electromagnetic fields they generate. It goes without saying that the issue has been raised whether radiofrequencies could be associated with tumorigenesis in humans, and in particular with brain tumors. To date, there is no direct evidence of this association, but some studies leave an open possibility. Metanalysis of epidemiological studies from Khurana et al. showed that the risk of ipsilateral gliomas and acoustic neuroma increased aproximately 2-fold in people using wireless phones for more than 10 years. The data did not achieve statistical significance for meningioma (90). Similarly, metanalyses studies from Levis and al., examining data on ipsilateral tumors in subjects using mobile phones since or for at least 10 years, showed increased risk of head tumors (91). The largest international case-control study on the use of mobile phones and risk of some tumors was commissioned by the WHO, and it is known as the INTERPHONE study. The study was conducted in 13 countries, includes the largest numbers of mobile phone users with at least 10 years of exposure, and focused on four types of tumors in tissues that most absorb RF energy emitted by mobile phones: tumors of the brain (glioma and meningioma), of the acoustic nerve (acoustic neuroma or schwannoma), and of the parotid gland. The study was concluded in 2012 with the following results: no increased risk of glioma or meningioma was observed with use of mobile phones, although there were suggestions of an increased risk of glioma at the highest exposure levels. No increased risk of acoustic neuroma was observed in regular users of a mobile phone or for users who began regular use 10 years or more before the reference date was observed. The effects of long-term heavy use of mobile phones still need further investigation. Data from parotid gland tumors were provided only from 3 countries, still with not significative results (92). Overall, the weak results provided by the studies on the effects of EMF on brain tumors do not allow to state that EMF are an established cause of cancer, and are therefore not addressed in the recommendations to reduce cancer risk (93). However, we may also want to consider that the field of technology is constantly evolving, and the possibility that the amount and type of radiation we are subjected to in daily life might cause or contribute to health problems and diseases in the long term, may still leave the question open.

\section{Food contaminants}

Food safety is also important when considering the development of certain diseases, including cancer. Food contaminants typically include contaminants from the environment, from food processing, from food packaging, and from the use of additives (94). We may not be able to examine all the variety of contaminants present in food, but we want to mention briefly some compounds for which certain effects on brain have been observed. We already mentioned the heavy metals and the effects they exert on brain. We also want to mention organochlorine compounds, which include DDT, lindane, and many other pesticides, which are lipophilic and resistant to degradation, and although their use was banned years ago, they still persist in the environment and contaminate food and water (95). Organochlorine compounds, as well as the dioxins, another group of toxic substances, have shown the potentiality to affect the brain development in infants and children, but a putative role in brain tumor development has not been demonstrated for any of them. For their effects on human health, the IARC classified organochlorine compounds and dioxins as probable human carcinogen (group 2B), and human carcinogen (group 1), respectively (IARC) (95). Food production process and cooking also represent a source of many toxic chemicals: a prime example are PAHs, occurring in smoked and grilled meat, other than from cigarette smoke and environmental contamination. Oxidative reactions convert PAHs in highly mutagenic and carcinogenic 
compounds $(95,96)$, which have known deleterious effects in organs and tissues such as lung and liver. Recently, PAHs exposure was associated with cortical thinning and decline in verbal learning and memory function in cognitively healthy adults, suggesting a role in neurodegeneration (96). N-nitroso compounds (NOCs) are another group of toxic substances, with the capability to alkylate DNA and demonstrated neuro-carcinogenicity in animal models (97). NOCs include nitrosamines and nitrosamides, which are endogenously formed in the stomach and intestine from intake of nitrite-preserved food, especially processed meat, and consumption of food with nitrites and nitrates, such as grain products and vegetables (98). Once in the bloodstream, they can affect different organs, and reach the brain. For these reasons, it has been hypothesized that a diet rich in nitrites and nitrates, by increasing the exposure to NOCs, could increase glioma risk (98). In the study from Dubrow et al, a large cohort of people $(545,770)$ participated in the prospective NIH-AARP Diet and Health Study, which assessed dietary intake of food such as high processed meat, nitrate, fruit and vegetables, at baseline (1995-96). During follow-up through 2003, 585 participants were diagnosed with glioma. The statistics revealed no positive risk of glioma associated with consumption of processed or red meat, nitrite, or nitrate; vitamin C or $\mathrm{E}$, and vegetables and fruit were neither providing protective effects against adult glioma risk (98). A different situation was reported instead by Dietrich et al, in relation to NOCs maternal exposure and risk of childhood brain tumor (99). In experimental rodents and monkeys, N-nitrosamides, rather than $\mathrm{N}$-nitrosamines, are the NOCs that likely can cause brain tumors, whereas $\mathrm{N}$-nitrosamines caused cancer in various animal species in a variety of organs but never in the brain. Epidemiologic literature is quite consistent in finding increased risk of childhood brain tumor associated with maternal intake of cured meats. However, further information is needed that takes into account additional dietary data, which should include the vast variety of foods, supplements, quantification of ingestion of nitrites and nitrates; sociodemographic factors, and more (99). Finally, we want to mention the largest combined prospective study, conducted in US and UK, on diet and risk of glioma, in which it has been shown that not significant association, if there is one, exists between major food groups and nutrients and risk of glioma (100).

\section{CONCLUSION REMARKS}

Brain cancers have always been object of intense study in the scientific community for several reasons: primarily, the fact that therapies are still not efficient, as compared to other types of cancer, and the mechanisms that induce these diseases are still not well understood. Brain cancers remains overall a very difficult type of neoplasm to face and defeat, and although diagnostic and therapeutic techniques and approaches are certainly evolving, the road to an effective solution is still long. Moreover, the efforts of the scientific community to identify any factor, occurring throughout the life of the human being and that may be the cause or a potential risk for these diseases, could represent a powerful tool for the adoption of preventative measures aimed at reducing the risk of exposure. A summary of the current status of classification of the aforementioned potential brain carcinogens is listed in table I. In addition table I displays, although not for brain cancer for most listed carcinogens, the U.S. EPA guidelines of exposure and potential routes of exposure. Note that only one chemical, acylonitrile, is validated as a brain carcinogen with corresponding permissible exposure limits of exposure. In addition to knowledge on potential carcinogenic mechanisms, the route of exposure has to be taken in consideration for proper risk assesment and

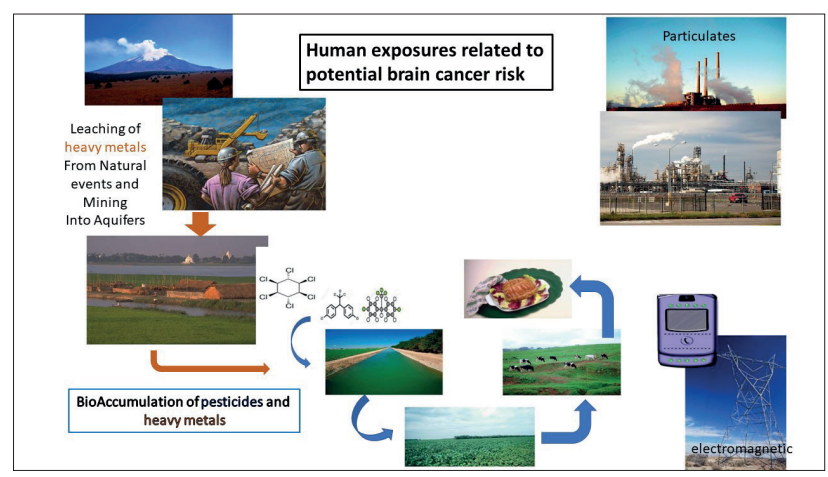

Figure 1. Sources of exposure of environmental contaminants potentially increasing risk of brain cancer. Represents the various sources of the aforementioned contaminants including, but not limited to, 1) leaching of heavy metals from volcanic ash and mining operations into drinking water sources 2) bioaccumulation of pesticides and herbicide contamination in food sources with resultant human consumption 3) particulate matter exposure from industrial sources (including hydrocarbon, benzene, and heavy metals and 4) potential harmful electromagnetic radiation from sources such as cell phone and electrical. Note that each source of potential contamination can result from particular exposures means such as inhalation or oral exposures. 


\begin{tabular}{|c|c|c|c|c|c|}
\hline $\begin{array}{l}\text { COMPOUND } \\
\text { CLASS }\end{array}$ & & IARC & NTP & EXPOSURE & $\begin{array}{l}\text { EPA DETERMINED } \\
\text { EXPOSURE LIMIT FOR } \\
\text { CARCINOGENICITY }\end{array}$ \\
\hline \multirow[t]{11}{*}{ Heavy Metals } & Compound & & & & \\
\hline & Aluminum production & 1 & & & \\
\hline & Arsenic, elemental & 1 & $\mathrm{~K}$ & $\begin{array}{l}\text { oral } \\
\text { inhalation }\end{array}$ & $\begin{array}{l}1.5 \mathrm{mg} / \mathrm{kg} / \text { day } \\
4.3 \times 10^{-3} \mathrm{mg} / \mathrm{m}^{3}\end{array}$ \\
\hline & Arsenic trioxide & 1 & $\mathrm{~K}$ & oral & 1.5 mg/kg-day \\
\hline & Cadmium elemental & 1 & $\mathrm{~K}$ & & \\
\hline & Lead acetate & & $\mathrm{R}$ & & \\
\hline & Lead and lead compounds & $2 \mathrm{~B}$ & & Oral & \\
\hline & Lead chromate & & $\mathrm{K}$ & & \\
\hline & Lead chromate (VI) & 1 & $\mathrm{~K}$ & inhalation & $1.2 \times 10^{-2} \mu \mathrm{g} / \mathrm{m}^{3}$ \\
\hline & Lead phosphate & $2 B$ & $\mathrm{R}$ & & \\
\hline & Manganese & ---- & ---- & & \\
\hline \multicolumn{6}{|c|}{ Organochlorine Insecticide/Pesticide } \\
\hline & DDT & 2B & $\mathrm{R}$ & $\begin{array}{l}\text { oral } \\
\text { inhalation }\end{array}$ & $\begin{array}{l}3.4 \times 10^{-1} \text { per } \mathrm{mg} / \mathrm{kg} \text {-day } \\
9.7 \times 10^{-5} \text { per } \mu g / \mathrm{m}^{3}\end{array}$ \\
\hline & DDE & $2 \mathrm{~B}$ & & oral & $3.4 \times 10^{-1}$ per $\mathrm{mg} / \mathrm{kg}$-day \\
\hline & DDD & $2 B$ & & oral & $2.4 \times 10^{-1}$ per $\mathrm{mg} / \mathrm{kg}$-day \\
\hline & heptachlor & $2 B$ & & oral & 4.5 per mg/kg-day \\
\hline & & & & inhalation & $1.3 \times 10^{-3}$ per $\mu g / \mathrm{m}^{3}$ \\
\hline & lindane & & $\mathrm{R}$ & & \\
\hline & $\begin{array}{l}\text { Polychlorinated biphenyl } \\
\text { (aroclor 1254) }\end{array}$ & $2 \mathrm{~A}$ & $\mathrm{R}$ & & \\
\hline & $\begin{array}{l}\text { Polychlorinated biphenyls } \\
\text { (PCB) }\end{array}$ & $2 \mathrm{~A}$ & $\mathrm{R}$ & inhalation & $\begin{array}{l}1 \times 10^{-4} \mu g / \mathrm{m}^{3} \text { (Low risk } \\
\text { and persistence) }\end{array}$ \\
\hline \multicolumn{6}{|l|}{ Other } \\
\hline & $\begin{array}{l}\text { Polycyclic aromatic } \\
\text { hydrocarbons (PAH) }\end{array}$ & & $\mathrm{R}$ & & \\
\hline & Nitrosamines (various) & 2B & $\mathrm{R}$ & oral & $2.8-22 \mathrm{mg} / \mathrm{kg} / \mathrm{day}$ \\
\hline & benzene & 1 & $\mathrm{~K}$ & oral & $5.5 \times 10^{-2}$ per $\mathrm{mg} / \mathrm{kg}$-day \\
\hline & & & & inhalation & $2.2 \times 10^{-6}$ per $\mu g / \mathrm{m}^{3}$ \\
\hline & Benzo[a]pyrene & $2 \mathrm{~A}$ & $\mathrm{R}$ & oral & 7.3 per mg/kg-day \\
\hline & Acrylonitrile* & $2 \mathrm{~B}$ & $\mathrm{R}$ & oral & $5.4 \times 10^{-1} \mathrm{mg} / \mathrm{kg}$-day \\
\hline $\begin{array}{l}\text { Particulate } \\
\text { matter }\end{array}$ & $\begin{array}{l}\text { PM } 2.5 \text { (particulate matter } \\
<2.5 \mathrm{~mm} \text { ) }\end{array}$ & & & inhalation & $12.0 \mu \mathrm{g} / \mathrm{m}^{3}$ per day \\
\hline
\end{tabular}

Table I. Carcinogenicity Classifications and Exposure Limits of Compounds Casually Involved in Brain Cancer Risk.

Exposure limits and carcinogenicity classifications were curated from the agencies websites National Toxicology Program (NTP, US Department of Health and Human Services) and the International Agency for Research on Cancer (IARC). The following is description for each agency classification: IARC: Group 1: carcinogenic to humans; Group 2A: probably carcinogenic to humans; Group 2B: possibly carcinogenic to humans. NTP: Group K: known to be human carcinogens Group R: reasonably anticipated to be human carcinogens. EPA: U.S. Environmental Protection Agency.

*An exposure limit has been established only for acrylonitrile for brain cancer. All other compounds the exposure level has been established for development of other types of cancers.

exposure limit guidelines (figure 1).

If from one side the scientific community has the duty to safeguard the human health, it is also true that it has to foster progress and technology, which are important resources for improving life quality and expectancy. But the progress 


\begin{tabular}{|c|c|c|c|}
\hline CHEMICAL & $\begin{array}{l}\text { OCCUPATIONAL/ } \\
\text { ENVIRONMENTAL } \\
\text { EXPOSURE }\end{array}$ & ROUTE OF EXPOSURE & TUMOR TYPE \\
\hline Asbestos & $\begin{array}{l}\text { Shipbuilding } \\
\text { Buildings, natural }\end{array}$ & Inhalation & mesothelioma \\
\hline Nickel & $\begin{array}{l}\text { Electroplating } \\
\text { Volcanic, fossil }\end{array}$ & Inhalation & Lung \& nasal carcinoma \\
\hline Chromate (VI) & $\begin{array}{l}\text { Welding } \\
\text { Anthropebic }\end{array}$ & $\begin{array}{l}\text { Inhalation } \\
\text { Inhalation, oral }\end{array}$ & $\begin{array}{l}\text { Lung } \\
\text { Lung, stomach? }\end{array}$ \\
\hline Benzene & $\begin{array}{l}\text { Chemical, gas } \\
\text { Gasoline, solvents }\end{array}$ & Inhalation & Leukemia and lymphomas \\
\hline Arsenic & $\begin{array}{l}\text { Pharma, mining } \\
\text { groundwater }\end{array}$ & $\begin{array}{l}\text { Inhalation } \\
\text { drinking water }\end{array}$ & $\begin{array}{l}\text { Lung cancer } \\
\text { Lung, bladder, skin, liver }\end{array}$ \\
\hline $\begin{array}{l}\text { Radioactive } \\
\text { substances }\end{array}$ & $\begin{array}{l}\text { Medical } \\
\text { Chernobyl }\end{array}$ & Whole body & $\begin{array}{l}\text { Thyroid }\left({ }^{125} \mid\right) \\
\text { Leukemia }\left({ }^{125} \mid 238 \cup{ }^{137} \mathrm{Cs}\right)\end{array}$ \\
\hline Coal tars & Roofing, paving & Dermal & Skin, bladder \\
\hline $\begin{array}{l}\text { Herbicides } \\
\text { Pesticides? }\end{array}$ & $\begin{array}{l}\text { Farming } \\
\text { Food, water }\end{array}$ & Dermal, oral, inhalation & Leukemias? \\
\hline
\end{tabular}

Table II. Occupational and Environmental Exposures of known human carcinogens with corresponding routes of exposure and resultant tumor types.

Known chemical exposures to be involved in human carcinogenesis and the various cancer types associated with either their most common occupational or environmental sources of contamination. Note that cancer type is also dependent on route of exposure. For example chromate inhalation is associated with nasal carcinoma yet ingestion of chromate is not associated with gastric or colon cancer. Occupational exposure, route of occupational exposure are italicized while Environmental exposure, route of environmental exposure are bolded.

may also have a cost impacting human lives that needs to be calculated. We cannot avoid eating, we cannot avoid being exposed to air pollutants, to electromagnetic radiation, and if we are able to calculate the consequences of such exposures, we may also adopt some measures and lifestyle to better protect ourselves. New technologies also contribute positively in our lives: for example, in medical field, the appropriate exposure to low frequency radiation led to better pain tolerance in the fight of fibromyalgia (101). Moreover, the application of inverted SMF to an in vitro model of hepatocellular carcinoma showed a synergistic anticancer activity with the natural compound capsaicin, opening the possibility of using SMF in cancer therapy (102). We are aware that the relationship between pollutants and brain cancer is a controversial matter: on one side there is the knowledge that some substances are indeed toxic, and on the other side we still lack a definitive demonstration of a causative association between certain compounds and the onset of brain tumors. Furthermore, we are also not totally aware of the mechanisms through which these compounds exert their toxicity at cellular level, and affect tissues and organs. In addition, many carcinogens exert specificity with regard to chemical form as well as subtype of cancer associated with said carcinogen. Table II shows many of the known environmental and occupational carcinogenic compounds, including hexavalent chromium and nickel compounds, have distinct tumorigenic potential for a given route of exposure. Brain tumors also represent an additional obstacle to these studies, due to the difficult accessibility to the site where these phenomena take place, the difficult to reproduce in vitro the same physiological condition of our body when studying these processes, and last but not least the presence of the BBB that make the CNS the safest place in our body from 
exogenous substances, but on the other hand it is the biggest obstacle in administering a therapy to try to save a human life. However, in recent years more studies provide increasing evidences toward a link for some pollutants with some brain tumors, especially for electromagnetic waves and particulate matter. A final consideration is toward the nature of these studies: most of these evidences come form metanalysis of epidemiological studies, which provide a more objective estimate than narrative reviews, increased statistical power, and allows a faster analysis of large amount of data. But a valid metanalysis needs to meet some requirements in the study strategy, since the conclusions achieved by metanalysis are affected by the methodological quality of the studies included in the analysis, by reporting biases, by the criteria of eligibility chosen for the study.

\section{REFERENCES}

1. Giglio P, Gilbert MR. Neurologic complications of cancer and its treatment. Curr Oncol Rep 2010;12(1):50-9.

2. Global, regional, and national burden of brain and other CNS cancer, 1990-2016: a systematic analysis for the Global Burden of Disease Study 2016. Lancet Neurol 2019;18(4):376-93.

3. Valvona $\mathrm{C}$, Fillmore $\mathrm{HL}$, Nunn $\mathrm{PB}$, Pilkington GJ. The Regulation and Function of Lactate Dehydrogenase A: Therapeutic Potential in Brain Tumor. Brain Pathol 2016;26(1):3-17.

4. Solanki C, Sadana D, Arimappamagan A, et al. Impairments in Quality of Life and Cognitive Functions in Long-term Survivors of Glioblastoma. J Neurosci Rural Pract 2017;8(2):228-35.

5. Sung H, Ferlay J, Siegel RL, et al. Global Cancer Statistics 2020: GLOBOCAN Estimates of Incidence and Mortality Worldwide for 36 Cancers in 185 Countries. CA Cancer J Clin 2021;71(3):209-49.

6. Farrell CJ, Plotkin SR. Genetic causes of brain tumors: neurofibromatosis, tuberous sclerosis, von Hippel-Lindau, and other syndromes. Neurol Clin 2007;25(4):925-46, viii.

7. Ionizing radiation, part $1: X$ - and gamma-radiation, and neutrons. Overall introduction. IARC Monogr Eval Carcinog Risks Hum 2000;75 Pt 1:35-115.

\section{ETHICS}

\section{Fundings}

This work was supported by the Sbarro Health Research Organization (http://www.shro.org).

\section{Conflicts of interests}

The authors have declared no conflict of interests.

\section{Authors' contribution}

$\mathrm{MM}$ and $\mathrm{VC}$ researched on the presented topic and wrote the manuscript. SJW also researched and cowrote the manuscript.

\section{Availability of data and material}

All the data supporting the findings of this study are available within the article.

8. Squillaro T, Galano G, De Rosa R, Peluso G, Galderisi U. Concise Review: The Effect of LowDose Ionizing Radiation on Stem Cell Biology: A Contribution to Radiation Risk. Stem Cells 2018;36(8):1146-53.

9. Hladik D, Tapio S. Effects of ionizing radiation on the mammalian brain. Mutat Res Rev Mutat Res 2016;770(Pt B):219-30.

10. Waters $M$, McKernan L, Maier A, Jayjock $M$, Schaeffer V, Brosseau L. Exposure Estimation and Interpretation of Occupational Risk: Enhanced Information for the Occupational Risk Manager. J Occup Environ Hyg 2015;12 (Suppl 1):S99-111.

11. Zumel-Marne A, Castano-Vinyals G, Kundi M, Alguacil J, Cardis E. Environmental Factors and the Risk of Brain Tumours in Young People: A Systematic Review. Neuroepidemiology 2019;53(3-4):121-41.

12. Pamphlett $R$, Kum Jew $S$. Inorganic mercury in human astrocytes, oligodendrocytes, corticomotoneurons and the locus ceruleus: implications for multiple sclerosis, neurodegenerative disorders and gliomas. Biometals 2018;31(5):807-19.

13. Moore AJ, Parker RJ, Wiggins J. Malignant mesothelioma. Orphanet J Rare Dis 2008;3:34.

14. Wurtz ET, Hansen J, Roe OD, Omland O. Asbestos exposure and haematological malignan- 
cies: a Danish cohort study. Eur J Epidemiol 2020;35(10):949-60.

15. Ding N, Zhou N, Zhou M, Ren GM. Respiratory cancers and pollution. Eur Rev Med Pharmacol Sci 2015;19(1):31-7.

16. White AJ, Bradshaw PT, Hamra GB. Air pollution and Breast Cancer: A Review. Curr Epidemiol Rep 2018;5(2):92-100.

17. Wang N, Mengersen K, Tong S, et al. Short-term association between ambient air pollution and lung cancer mortality. Environ Res 2019;179(Pt A):108748.

18. Deng $H$, Eckel SP, Liu L, Lurmann FW, Cockburn MG, Gilliland FD. Particulate matter air pollution and liver cancer survival. Int J Cancer 2017;141(4):744-9.

19. Andreotti G, Silverman DT. Occupational risk factors and pancreatic cancer: a review of recent findings. Mol Carcinog 2012;51(1):98-108.

20. Manisalidis I, Stavropoulou E, Stavropoulos A, Bezirtzoglou E. Environmental and Health Impacts of Air Pollution: A Review. Frontiers in Public Health 2020;8:14.

21. Hamanaka RB, Mutlu GM. Particulate Matter Air Pollution: Effects on the Cardiovascular System. Front Endocrinol (Lausanne) 2018;9:680.

22. Adams K, Greenbaum DS, Shaikh R, van Erp AM, Russell AG. Particulate matter components, sources, and health: Systematic approaches to testing effects. J Air Waste Manag Assoc 2015;65(5):544-58.

23. Oppenheim HA, Lucero J, Guyot AC, et al. Exposure to vehicle emissions results in altered blood brain barrier permeability and expression of matrix metalloproteinases and tight junction proteins in mice. Part Fibre Toxicol 2013;10:62.

24. Oberdorster G, Sharp Z, Atudorei V, et al. Translocation of inhaled ultrafine particles to the brain. Inhal Toxicol 2004;16(6-7):437-45.

25. Andersen ZJ, Pedersen M, Weinmayr G, et al. Long-term exposure to ambient air pollution and incidence of brain tumor: the European Study of Cohorts for Air Pollution Effects (ESCAPE). Neuro Oncol 2018;20(3):420-32.

26. Heusinkveld HJ, Wahle T, Campbell $A$, et al. Neurodegenerative and neurological disorders by small inhaled particles. Neurotoxicology 2016;56:94-106.

27. Calderon-Garciduenas L, Solt AC, Henriquez-Roldan C, et al. Long-term air pollution exposure is associated with neuroinflammation, an altered innate immune response, disruption of the blood-brain barrier, ultrafine particulate deposition, and accumulation of amyloid beta42 and alpha-synuclein in children and young adults. Toxicol Pathol 2008;36(2):289-310.

28. Block ML, Calderon-Garciduenas L. Air pollution: mechanisms of neuroinflammation and CNS disease. Trends Neurosci 2009;32(9):506-16.

29. Weichenthal S, Olaniyan T, Christidis $T$, et al. Within-city Spatial Variations in Ambient Ultrafine Particle Concentrations and Incident Brain Tumors in Adults. Epidemiology 2020;31(2):177-83.

30. Jorgensen JT, Johansen MS, Ravnskjaer $L$, et al. Long-term exposure to ambient air pollution and incidence of brain tumours: The Danish Nurse Cohort. Neurotoxicology 2016;55:122-30.

31. Wu AH, Wu J, Tseng C, et al. Association Between Outdoor Air Pollution and Risk of Malignant and Benign Brain Tumors: The Multiethnic Cohort Study. JNCl Cancer Spectr 2020;4(2):pkz107.

32. Tchounwou PB, Yedjou CG, Patlolla AK, Sutton DJ. Heavy metal toxicity and the environment. Exp Suppl 2012;101:133-64.

33. Arita A, Costa M. Epigenetics in metal carcinogenesis: nickel, arsenic, chromium and cadmium. Metallomics 2009;1(3):222-8.

34. Alissa EM, Ferns GA. Heavy metal poisoning and cardiovascular disease. J Toxicol 2011;2011:870125.

35. Chen P, Miah MR, Aschner M. Metals and Neurodegeneration. F1000Res. 2016;5.

36. Orr SE, Bridges CC. Chronic Kidney Disease and Exposure to Nephrotoxic Metals. Int J Mol Sci. 2017;18(5).

37. Dermience M, Lognay G, Mathieu F, Goyens P. Effects of thirty elements on bone metabolism. J Trace Elem Med Biol 2015;32:86-106.

38. Mason LH, Harp JP, Han DY. Pb neurotoxicity: neuropsychological effects of lead toxicity. Biomed Res Int 2014;2014:840547.

39. Caffo M, Caruso G, Fata GL, et al. Heavy metals and epigenetic alterations in brain tumors. Curr Genomics 2014;15(6):457-63.

40. Gilani SR, Zaidi SR, Batool M, Bhatti AA, Durrani Al, Mahmood Z. Report: Central nervous system (CNS) toxicity caused by metal poisoning: Brain as a target organ. Pak J Pharm Sci 2015;28(4):1417-23.

41. Gaman L, Radoi MP, Delia CE, et al. Concentration of heavy metals and rare earth elements in patients with brain tumours: Analysis in tu- 
mour tissue, non-tumour tissue, and blood. Int J Environ Health Res 2019:1-14.

42. Schlehofer B, Hettinger I, Ryan $P$, et al. Occupational risk factors for low grade and high grade glioma: results from an international case control study of adult brain tumours. Int J Cancer 2005;113(1):116-25.

43. Rossman TG, Klein CB. Genetic and epigenetic effects of environmental arsenicals. Metallomics. 2011;3(11):1135-41.

44. Rajaraman P, Stewart PA, Samet JM, et al. Lead, genetic susceptibility, and risk of adult brain tumors. Cancer Epidemiol Biomarkers Prev 2006;15(12):2514-20.

45. Navas-Acien A, Pollan M, Gustavsson P, Plato N. Occupation, exposure to chemicals and risk of gliomas and meningiomas in Sweden. Am J Ind Med 2002;42(3):214-27.

46. Chen X, Guo C, Kong J. Oxidative stress in neurodegenerative diseases. Neural Regen Res 2012;7(5):376-85.

47. Collin F. Chemical Basis of Reactive Oxygen Species Reactivity and Involvement in Neurodegenerative Diseases. Int J Mol Sci 2019;20(10):2407.

48. Butterfield DA, Boyd-Kimball D. Oxidative Stress, Amyloid-beta Peptide, and Altered Key Molecular Pathways in the Pathogenesis and Progression of Alzheimer's Disease. J Alzheimers Dis 2018;62(3):1345-67.

49. Bosco DA, Fowler DM, Zhang Q, et al. Elevated levels of oxidized cholesterol metabolites in Lewy body disease brains accelerate alpha-synuclein fibrilization. Nat Chem Biol 2006;2(5):249-53.

50. Xu J, Wise JTF, Wang L, Schumann K, Zhang Z, Shi X. Dual Roles of Oxidative Stress in Metal Carcinogenesis. J Environ Pathol Toxicol Oncol 2017;36(4):345-76.

51. Martinez-Zamudio R, Ha HC. Environmental epigenetics in metal exposure. Epigenetics 2011;6(7):820-7.

52. Ali AH, Kondo K, Namura T, et al. Aberrant DNA methylation of some tumor suppressor genes in lung cancers from workers with chromate exposure. Mol Carcinog 2011;50(2):89-99.

53. Garcia-Guede A, Vera O, Ibanez-de-Caceres I. When Oxidative Stress Meets Epigenetics: Implications in Cancer Development. Antioxidants (Basel) 2020;9(6).

54. Nishida N, Kudo M. Oxidative stress and epigenetic instability in human hepatocarcinogenesis. Dig Dis. 2013;31(5-6):447-53.
55. Franco R, Schoneveld O, Georgakilas AG, Panayiotidis MI. Oxidative stress, DNA methylation and carcinogenesis. Cancer Lett 2008;266(1):6-11.

56. Nishida N, Arizumi T, Takita $M$, et al. Reactive oxygen species induce epigenetic instability through the formation of 8-hydroxydeoxyguanosine in human hepatocarcinogenesis. Dig Dis 2013;31(5-6):459-66.

57. Lin YH. MicroRNA Networks Modulate Oxidative Stress in Cancer. Int J Mol Sci 2019;20(18).

58. Finicelli M, Squillaro T, Galderisi U, Peluso G. Micro-RNAs: Crossroads between the Exposure to Environmental Particulate Pollution and the Obstructive Pulmonary Disease. Int J Mol Sci 2020;21(19).

59. Sima M, Rossnerova A, Simova Z, Rossner $P$, Jr. The Impact of Air Pollution Exposure on the MicroRNA Machinery and Lung Cancer Development. J Pers Med 2021;11(1).

60. Stojsavljevic A, Vujotic L, Rovcanin B, Borkovic-Mitic S, Gavrovic-Jankulovic M, Manojlovic D. Assessment of trace metal alterations in the blood, cerebrospinal fluid and tissue samples of patients with malignant brain tumors. Sci Rep 2020;10(1):3816.

61. Arslan M, Demir H, Arslan H, Gokalp AS, Demir C. Trace elements, heavy metals and other biochemical parameters in malignant glioma patients. Asian Pac J Cancer Prev 2011;12(2):447-51.

62. ATSDR.ATSDR Substance Priority List 2017. Available from: https://www.atsdr.cdc.gov/ spl/. Last access: Sept 29, 2021.

63. Rice KM, Walker EM, Jr., Wu M, Gillette C, Blough ER. Environmental mercury and its toxic effects. J Prev Med Public Health 2014;47(2):74-83.

64. Crespo-Lopez ME, Macedo GL, Pereira SI, et al. Mercury and human genotoxicity: critical considerations and possible molecular mechanisms. Pharmacol Res 2009;60(4):212-20.

65. Ray PD, Yosim A, Fry RC. Incorporating epigenetic data into the risk assessment process for the toxic metals arsenic, cadmium, chromium, lead, and mercury: strategies and challenges. Front Genet 2014;5:201.

66. Boffetta P, Merler E, Vainio H. Carcinogenicity of mercury and mercury compounds. Scand J Work Environ Health 1993;19(1):1-7.

67. Ahlbom A, Norell S, Rodvall $Y$, Nylander M. Dentists, dental nurses, and brain tumours. $\mathrm{Br}$ Med J (Clin Res Ed) 1986;292(6521):662.

68. Inorganic and organic lead compounds. IARC Monogr Eval Carcinog Risks Hum 2006;87:1-471. 
69. Sharma P, Chambial S, Shukla KK. Lead and neurotoxicity. Indian J Clin Biochem 2015;30(1):1-2.

70. Eid A, Zawia N. Consequences of lead exposure, and it's emerging role as an epigenetic modifier in the aging brain. Neurotoxicology 2016;56:254-61.

71. Steenland K, Barry V, Anttila A, et al. Cancer incidence among workers with blood lead measurements in two countries. Occup Environ Med 2019;76(9):603-10.

72. Gwini S, MacFarlane E, Del Monaco A, et al. Cancer incidence, mortality, and blood lead levels among workers exposed to inorganic lead. Ann Epidemiol 2012;22(4):270-6.

73. Barry V, Steenland K. Lead exposure and mortality among U.S. workers in a surveillance program: Results from 10 additional years of follow-up. Environ Res 2019;177:108625.

74. Bhatti P, Stewart PA, Linet MS, Blair A, Inskip PD, Rajaraman P. Comparison of occupational exposure assessment methods in a case-control study of lead, genetic susceptibility and risk of adult brain tumours. Occup Environ Med 2011;68(1):4-9.

75. Lam TV, Agovino P, Niu X, Roche L. Linkage study of cancer risk among lead-exposed workers in New Jersey. Sci Total Environ 2007;372(23):455-62.

76. Ahn J, Park MY, Kang MY, Shin IS, An S, Kim HR. Occupational Lead Exposure and Brain Tumors: Systematic Review and Meta-Analysis. Int J Environ Res Public Health 2020;17(11).

77. Sanders T, Liu Y, Buchner V, Tchounwou PB. Neurotoxic effects and biomarkers of lead exposure: a review. Rev Environ Health 2009;24(1):15-45.

78. Lugo-Huitron R, Ugalde Muniz P, Pineda B, Pedraza-Chaverri J, Rios C, Perez-de la Cruz V. Quinolinic acid: an endogenous neurotoxin with multiple targets. Oxid Med Cell Longev 2013:2013:104024.

79. Liao LM, Friesen MC, Xiang YB, et al. Occupational Lead Exposure and Associations with Selected Cancers: The Shanghai Men's and Women's Health Study Cohorts. Environ Health Perspect 2016;124(1):97-103.

80. Reisz JA, Bansal N, Qian J, Zhao W, Furdui CM. Effects of ionizing radiation on biological molecules-mechanisms of damage and emerging methods of detection. Antioxid Redox Signal 2014;21(2):260-92.
81. Radiation Studies Ionizing Radiation. Available from: https://www.cdc.gov/nceh/radiation/ionizing_radiation.html. Last access: Sept 21, 2021.

82. Leroi N, Lallemand F, Coucke P, Noel A, Martinive P. Impacts of lonizing Radiation on the Different Compartments of the Tumor Microenvironment. Front Pharmacol 2016;7:78.

83. Ozdemir F, Kargi A. Electromagnetic Waves and Human Health 2011.

84. Calabrò E. Introduction to the Special Issue "Electromagnetic Waves Pollution". Sustainability 2018;10(9):3326.

85. Kinouchi Y, Yamaguchi H, Tenforde TS. Theoretical analysis of magnetic field interactions with aortic blood flow. Bioelectromagnetics 1996;17(1):21-32.

86. Pacini $S$, Gulisano M, Peruzzi B, et al. Effects of $0.2 \mathrm{~T}$ static magnetic field on human skin fibroblasts. Cancer Detect Prev 2003;27(5):327-32.

87. Zhang QM, Tokiwa M, Doi T, et al. Strong static magnetic field and the induction of mutations through elevated production of reactive oxygen species in Escherichia coli soxR. Int J Radiat Biol 2003;79(4):281-6.

88. Calabro E, Condello S, Curro M, et al. Effects of low intensity static magnetic field on FTIR spectra and ROS production in SH-SY5Y neuronal-like cells. Bioelectromagnetics 2013;34(8):618-29.

89. Baldi I, Coureau G, Jaffre A, et al. Occupational and residential exposure to electromagnetic fields and risk of brain tumors in adults: a case-control study in Gironde, France. Int J Cancer 2011;129(6):1477-84.

90. Khurana VG, Teo C, Kundi M, Hardell L, Carlberg M. Cell phones and brain tumors: a review including the long-term epidemiologic data. Surg Neurol 2009;72(3):205-14; discussion 14-5.

91. Levis AG, Minicucci N, Ricci P, Gennaro V, Garbisa S. Mobile phones and head tumours: it is time to read and highlight data in a proper way. Epidemiol Prev 2011;35(3-4):188-99.

92. Vijayalaxmi, Prihoda TJ. Mobile phones, non-ionizing radiofrequency fields and brain cancer: is there an adaptive response? Dose Response 2014;12(3):509-14.

93. McColl N, Auvinen A, Kesminiene A, et al. European Code against Cancer 4th Edition: Ionising and non-ionising radiation and cancer. Cancer Epidemiol 2015;39 Suppl 1:S93-100.

94. Rather IA, Koh WY, Paek WK, Lim J. The Sources of Chemical Contaminants in Food and Their Health Implications. Front Pharmacol 2017;8:830. 
95. Borchers A, Teuber SS, Keen CL, Gershwin ME. Food safety. Clin Rev Allergy Immunol 2010;39(2):95-141.

96. Cho J, Sohn J, Noh J, et al. Association between exposure to polycyclic aromatic hydrocarbons and brain cortical thinning: The Environmental Pollution-Induced Neurological EFfects (EPINEF) study. Sci Total Environ 2020;737:140097.

97. Veena S, Rashmi S. A review on mechanism of nitrosamine formation, metabolism and toxicity in in vivo. Int J Toxicol Pharmacol Res 2014;6:86-96.

98. Dubrow R, Darefsky AS, Park Y, et al. Dietary components related to $\mathrm{N}$-nitroso compound formation: a prospective study of adult glioma. Cancer Epidemiol Biomarkers Prev 2010;19(7):1709-22.
99. Dietrich M, Block G, Pogoda JM, Buffler P, Hecht $S$, Preston-Martin S. A review: dietary and endogenously formed $\mathrm{N}$-nitroso compounds and risk of childhood brain tumors. Cancer Causes Control 2005;16(6):619-35.

100.Kuan AS, Green J, Kitahara CM, et al. Diet and risk of glioma: combined analysis of 3 large prospective studies in the UK and USA. Neuro Oncol. 2019;21(7):944-52.

101.Paolucci T, Piccinini G, losa M, et al. Efficacy of extremely low-frequency magnetic field in fibromyalgia pain: A pilot study. J Rehabil Res Dev 2016;53(6):1023-34.

102.Cheng Y, Muroski ME, Petit D, et al. Rotating magnetic field induced oscillation of magnetic particles for in vivo mechanical destruction of malignant glioma. J Control Release 2016;223:75-84. 